\title{
Improve Chinese Ability to Promote Development in Job Market
}

\author{
Liwei Fu \\ School of Humanities \\ Xi'an Peihua University \\ 710125 Xi'an, Shanxi, China
}

\begin{abstract}
Chinese ability plays an important role in the job interview, career promotion and career transformation of the graduates. However, nowadays, there is a general situation of "awkward expression", "negligent expression" and "embarrassed to express", so it is difficult to meet the requirements of the employers. In the last two years, through the construction of multiple classes, the development of outside school activities and the use of network resources, our school has improved the students' Chinese ability, and the effect is obvious. The research of this subject has made some contribution to the Chinese education in colleges and universities.
\end{abstract}

Keywords—job market; Chinese ability; multiple classroom; outside school practice; network resources

\section{INTRODUCTION}

In 1998, the Ministry of Labor and Social Security in our country divided the occupational core competencies into 8 items in the National Skills Revitalization Strategy, of which "communication and presentation skills" ranked first. Today, with the global economic integration trend and our country's "One Belt and One Road" strategic background, the exchange of information has become increasingly frequent, regardless of whether it is between countries, enterprises or individuals. Good expression is not only the embodiment of national comprehensive quality, but also can build a win-win relationship for enterprises and institutions to promote the healthy development of enterprises and institutions.[1]

\section{The Role of Chinese AbILITy IN The Development of THE JOB MARKET}

Chinese is the most important communicative tool in our work. Good Chinese ability not only reflects in the accurate, smooth and precise use of Chinese, but also an outward manifestation of clear mind and quick thinking. National Occupation Chinese Language Proficiency Test Center made it clear that Chinese ability can show one's ability of communication and thinking, problem-solving and relearning, future work performance and development potential. [2] Therefore, it has become an important indicator of employment of enterprises and institutions. Proficient Mandarin and excellent articles will surely help graduates achieve significant growth in the job market.

Foundation project: 2017 School-level research projects "The Value and Training Path Research of Chinese Expressive Ability in the Image Shaping of Undergraduates' Employability" of Xi'an Peihua University, the project number is PHKT17074.

\section{A. Image shaping in job interview}

Social demands for talent are getting higher and higher. In the process of job hunting, due to lack of rich social experience, college graduates are often rejected. However, good Chinese expression can quickly arouse the attention of the employers.[3] Natural, smooth, graceful and precise expressions can fully demonstrate graduates 'solid foundation of language skills, clear-cut thinking habits and rigorous and orderly logic, and the employing units can see the graduates' solid strength and hidden potential in a short period of time. It is not difficult to find that calm and concise conversation and clear and concise resumes can help us to create a excellent job hunting figures. This is an issue that all current graduates and educators must pay attention to.

\section{B. Interpersonal communication in the promotion of job market}

Promotion not only means more generous salary and more comfortable working environment, but also is an important embodiment of its own value added. Ability to deal with complex interpersonal relationships is also an important factor to represent soft power of graduates apart from their excellent professional skills if they want to be promoted in the job market. Active and effective communication can create good interpersonal relationships for yourself. Negative and ineffective dialogue can only become an obstacle to career promotion. Mastering the basic workplace communication skills can make us a tiger with wings added at work. Sincere, courteous, honest, well-organized, clear headed, focused, appropriate and efficient communication is undoubtedly an important condition for promotion in the job market.

\section{Escort in the career transformation}

With the development of industry, the career transformation has become a problem that many students will meet after graduation in the fast running society. Career transformation is commonly called 'job hopping", to some extent represents "job clearance", which means abandoning accumulation and exposing to a certain degree of risk. However, daring to break through the limits can be a new opportunity for self-escalation and it can be a new opportunity for self-upgrading. From one industry to another industry, the content and process of job may change, but the application of the Chinese is still the same. Good Chinese skills can help students open up a new situation in a new environment, establish healthy interpersonal 
relationships, quickly understand and adapt to the new working environment and meet bigger challenges to escort our career transformation.

To sum up, no matter what industry we are engaged in, no matter where it is in the job market, Chinese ability will be an important part of students' comprehensive strength. Good Chinese ability can do what little one can to help students' career development.

\section{The Present Situation of College Students' Chinese ABILITY}

According to a survey conducted by the China Social Surveys (SSIC), 32\% of the students felt it 'hard to start when writing their essay," $31 \%$ of them "failed to chatting with strangers leisurely," and only 25\% thought "their own language skills are strong." [4] Thus, the current situation of college students' Chinese ability is not optimistic, and there is still a big gap between social needs. According to the survey, there are several conditions for the Chinese students' Chinese ability today:

\section{A. Clumsy in expression}

"Clumsy in expression" refers to the undergraduates' lack of Chinese proficiency. When students express their views or thoughts and feelings, some of them expressed vaguely and confusedly, some are lacking in emphasis and contradictions and some even expressed incoherently, which makes people puzzled. [5] Through observation, even a student who is majored in Chinese language and literature, it is surprising that a large number of typos and ill sentences will occur when writing graduation thesis. It is not difficult to find that the gradual decline of Chinese ability of college students has become an indisputable fact and it is hardly possible to meet the demand of employers for talents.

\section{B. Lack of expression}

"Lack of expression" refers to express little. On the one hand, some students were influenced by the traditional culture of our country, regarding "less talk and more action" as virtue and reminding themselves "self-preservation", "curse of mouth" and "it is better to say less and it's best to say nothing".[6] On the other hand, in the era of rapid network development, a large number of bubble-like online expressions and facial expression packs hit us all over the world. Young college students are influenced by their mentality and replace the original complex sentence with the popular pattern of language and images, reducing brain activity and resulting in continued degradation of Chinese ability. [7]

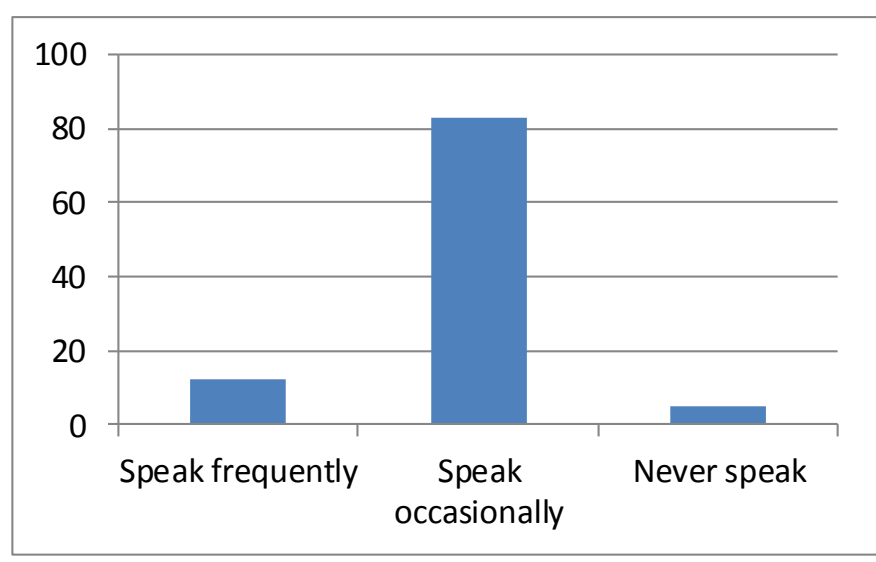

Fig. 1. 2015 students' speak offhand of Culture Institute in Xi'an Peihua University

The above is a questionnaire survey of students in grade 2015 of our Culture Institute, in which 12\% of the students who speak frequently, $83 \%$ of the total number of students who speak occasionally, and $5 \%$ of the students never speak. Thus it can be seen that "lack of expression" has become a common phenomenon in college students' classrooms.

After entering the job market, most of the work needs to be dealt with people, and students are asked to express and communicate to solve the problems that arise in the work. "Lack of expression" makes it hardly possible to promote the normal operation of the work and it will also become an obstacle to the establishment of interpersonal relationship.

\section{Be ashamed to express}

Nowadays, college students frequently use virtual network platform to communicate with each other with much fragmented language and little serious and standardized language. The lack of repeated practice of the real environment results in a nervous and timid mentality of students in public and formal occasions.

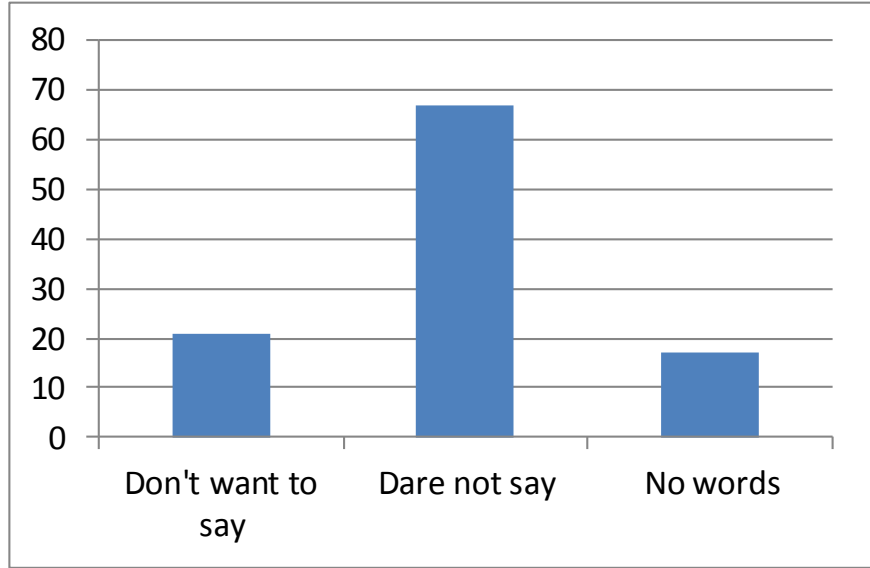

Fig. 2. The reasons for the few speak of 2015 students of Culture Institute in Xi'an Peihua University 
The figure above shows our follow-up survey of students who "dare not say" and "have no words". The results showed that $67 \%$ of the classmates "dare not to say" even in the classroom when they were familiar with their classmates. With the development of society, communication skills become more and more important. It is difficult for students to be satisfied with the employers in the job market with the state of "ashamed to express".

In order to change the current situation that students are "clumsy in expression," "lacking of expression" and "ashamed to express", and cultivate graduates to be suitable for social development, educators should consider seriously and follow the trend of the times to find effective ways of education.

\section{Strategies to Improve College Students' Chinese} ABILITY

\section{A. Construct multiple classroom mode}

In order to improve the students' Chinese ability, teachers can start from teaching, change their traditional ideas and construct multiple classes to meet the needs of the society.

\section{1) Diversify teaching design}

Whether it is a professional course or a public lesson, teachers should change the mode "one person lays down the law", and "taking teachers as the leading role and taking students as the main body" to make the teaching design diversified. In the reform of applied curriculum in our school, we adjusted the proportion of traditional teaching methods, used "Micro-Course Online Video" and "MOOC" resources, introduced "flip classroom" "STEAM education" and other advanced concepts, breaking the boring traditional classroom and improving students' Chinese ability.

For example, we integrate "Chinese language" education concept into College Chinese courses, improve the teaching mode based on the appreciation of ancient poetry, reorganize the teaching content, closely connect with the career of the students in the future to improve the students' Chinese ability in an all-round way and meet the needs of different industries. When teaching 'the way of the great learning involves manifesting virtue, loving the people, and abiding by the highest good" in The book of Rites, we required students to translate and explain in the classroom and guided students to interview the "virtue" people and wrote articles or shoot micro films according to the interview, which increased students' understanding of the industry and exercised their oral and written expression skills. Taking another example, in the reform of professional courses, we can fully mobilize the enthusiasm and initiative of students, and integrate boring theories into vivid scenes; enabling students can not only learn professional knowledge but also improve their Chinese abilities. Simulating criminal, civil, administrative trial and arbitration process through the analysis of the merits, division of roles, preparation of legal instruments, rehearsals, formal sessions and other sectors, which has mobilized the participation and creativity of students, improved the writing ability of legal documents and the ability to defend the court hearing. In the repeated training of classroom teaching, students has been transformed from "do not want to say, dare not to say and no words" to "have to say", and finally show the state of "rushing to speak", and Chinese ability has been improved naturally.

\section{2) Diversify evaluation system}

The reform of teaching mode is inseparable from the reform of the evaluation system, breaking the singularity and limitations of the teachers' and students' way of judging ability according to the scores of papers only, taking the multiple evaluation system as the baton and giving full play to the role of teachers' restraint and guidance to truly implement qualityoriented education. In recent two years, our school has changed the traditional ratio that ordinary performance accounts $30 \%$ and final results accounts $70 \%$, increased the proportion of the ordinary performance according to the nature of the course, even replaced the final examination with a full process examination model for part of the course, distributed scores on regular statements, team work, final results, and final reporting to enable students to exercise the ability of communication and cooperation with others in completing their lessons, and constantly overcome the timid psychology of speaking in public, so that students can effectively improve their Chinese ability while training professional skills. Besides, we organize various Chinese competitions in the whole school, such as debating, speaking, and writing competitions. We choose excellent students to set examples and encourage students to improve their Chinese abilities.

In the 2017 Final Freshmen Symposium, we found that students are extremely positive about the multiple classroom mode. They not only saw the difference between the multiple classroom mode and the traditional classroom mode, but also fully realized the important role of Chinese ability in the future job market. In the meantime, they transformed from "passive speaking and writing" to "positive speaking and writing" and from "nothing to say" to 'free speak", really feeling the improvement of Chinese ability.

\section{B. Actively organize off-campus practical activities}

In addition to changing the classroom teaching mode, we can also provide school-going students opportunities to go to the society, carry out school enterprise cooperation extensively, help students get exercise in real job market, and guide students to apply book knowledge to practical work. In this process, students must expand effective communication and cooperation with real professionals when leaving familiar campus environment and family environment and facing a strange and real working environment and specific tasks. They will pay more attention to the appropriateness, standardization and clarity of language than ever before, so as to further improve their Chinese ability. Our school relies on student associations and off campus bases, and continues to carry out off campus practice activities for freshmen to senior four students, which can improve students' professional skills and Chinese level in the process. Taking Chinese language and literature major as an example, our department signed a base agreement with a number of primary and secondary schools around to arrange senior students internship lectures, which requires students to correctly and standardize their language skills, train their teachers 'language skills, develop students' adaptive abilities in advance, and seamlessly integrate their studies with their careers. 


\section{Make full use of network resources}

Nowadays, with the rapid development of science and technology, computers, smart phones and network resources have covered almost every university. Teachers can guide students to improve their Chinese language skills by using network technology and resources. In our teaching process, teachers guide students to correct their incorrect pronunciation by "listening" through "Himalayas" APP and other audio resources, pertinently carry out intensive training by "speaking" for self-testing with "Mandarin Practice Room" and other software, improve language understanding and analytical skills and increase the knowledge base by "reading" through WeChat subscription and other online media for fragmented reading and express profound views and opinions in a standardized language and continuously improve Chinese language ability by cultivating the habit of "writing" with the message area of the internet platform. Under the continuous help and supervision of the teachers, the students' ability to listen, speak, read and write Chinese has been greatly improved. When we improve teaching mode and extend the boring classroom education to a great quantity of network resources, we can fully stimulate students 'interest in learning, cultivate students' awareness of learning and improve our Chinese teaching effectiveness.

\section{CONCLUSION}

The three methods are complementary to each other, which can be used to improve the students' Chinese ability from different angles. Construction of the multi-class mode students 'enthusiasm for learning and stimulate students' independent participation and positive performance. The practice of extracurricular activities can help students transform Chinese theory of the book into an operable expression skill and practical exercise. In daily life, students can make use of fragmented time and combine network technology and Internet resources to further improve their Chinese abilities in listening, speaking, reading and writing. Through continuous efforts, students can change from "clumsy in expression" to "diligence in expression" and from "be ashamed of expression" to "skilled in expression", which will finally promote the career development.

\section{REFERENCES}

[1] Li Chengsen. The Construction of Higher Vocational Students Language Ability Based on Vocational Needs[J].Liaoning Higher Vocational Technical Institute Journal, 2016 (09): 73-75;

[2] https://baike.so.com/doc/6729168-6943458.html;

[3] Zhou Chaofan and Gong Ping. Study on the Current Situation and Promotion Strategy of College Students' Language Ability - A Case Study of Hotel Management Major in Hainan University[J].Jiangsu Science \& Technology Information, 2016 (03): 48-50;

[4] Li Haichao. Status Quo and Strategies of College Students' Language Ability[J].Higher Education Development and Evaluation, 2009 (11): 100-104;

[5] Zhang Guomin, Wu Yingyao and Zhao Fuming. Attention Should Be Paid to the Cultivation of the Language Expression Ability of College Students[J]. Journal of Shan xi Agricultural University (Social Science Edition), 2003 (02): 268-274.

[6] Zhang Duan. How to Strengthen College Students' Ability of Language Expression in Modern Chinese Teaching[J]. Language Planning, 2013 (07): 19-20;

[7] Hou Zhan xiang. Students' Language Ability in New Media Era Urgently Needs to Be Improved[J]. Marketing Research, 2016(03):13-14. 